\title{
PENGARUH GUIDED IMAGARY TERHADAP PENURUNAN RASA NYERI PADA PENDERITA GASTRITIS DI RUMAH SAKIT UMUM ROYAL PRIMA MEDAN
}

\section{Robbialwy Sembiring ${ }^{1}$, Ema Novelia ${ }^{2}$, Merisusanna Sinuhaji ${ }^{3}$, Chrismis Novalinda Ginting ${ }^{4}$}

\author{
${ }^{1,2,3}$ Mahasiswa S1 Keperawatan Fakultas Keperawatan Dan Kebidanan Universitas \\ Prima Indonesia \\ Email : emanovelia02@gmail.com \\ ${ }^{4}$ Dosen Fakultas Keperawatan dan kebidanan Universitas Prima Indonesia \\ Email : chrismis@unprimdn.ac.id
}

\section{ABSTRACT : INFLUENCE OF GUIDED IMAGERY ON PAIN DECREASE IN GASTRITIS PATIENTS IN ROYAL PRIMA MEDAN GENERAL HOSPITAL}

Background : Gastritis is an irritation in the stomach that causes pain in sufferers. In general, people do not recognize gastritis, but more often say heartburn. Pain is the body's response to pain. There are several actions that can be done in overcoming pain, one of them is Guided Imagary therapy, a safe solution for patients without side effects, because this therapy processes thinking by focusing on pleasant things.

Pupose: To determine the effect of guided imagery on pain reduction in patients with gastritis at the Royal Prima General Hospital.

Method : type this research is research analytic descriptive with one group design pre and post test, Post test research found a majority of 18 respondents $(47.4 \%)$ and a minority of severe pain 3 respondents $(7.9 \%)$. The value of sig (2tailed) $=0,000$ and $\mathrm{a}=0.05$, then $0,000<0.05$ then Ho is accepted Ha means that there is a Guided Imagery effect on pain reduction in gastritis at Royal Prima Medan General Hospital. According to Notoadmojo (2010) The population is the whole object under study, in this study were all gastritis patients in the inpatient room of the Royal Prima General Hospital, amounting to 38 people. Samples were 38 gastritis patients in the inpatient room of Royal Prima General Hospital. The sampling technique uses total sampling in which the entire population is sampled.

Results: The majority of moderate pain and severe pain pre-test research were 17 respondents $(44.7 \%)$, and the minority had no pain and mild pain 2 respondents $(5.3 \%)$. Post test research found a majority of 18 respondents (47.4\%) and a minority of severe pain 3 respondents $(7.9 \%)$. The value of sig (2tailed) $=0,000$ and $\mathrm{a}=0.05$, then $0,000<0.05$ then Ho is accepted Ha means that there is a Guided Imagary effect on pain reduction in gastritis at Royal Prima Medan General Hospital.

Conclusion: That there is an effect of Guided Imagery on the reduction of pain in patients with gastritis.

Keywords: Gastritis, Pain, Guided Imagery Technique.

\footnotetext{
Robbialwy Sembiring ${ }^{1}$, Ema Novelia ${ }^{2}$, Merisusanna Sinuhaji ${ }^{3}$, Chrismis Novalinda Ginting $^{4}$ ${ }_{1,2,3}$ Mahasiswa S1 Keperawatan Universitas Prima Indonesia. Email : emanovelia02@gmail.com ${ }^{4}$ Dosen Universitas Prima Indonesia. Email : chrismis@unprimdn.ac.id
} 
INTISARI : PENGARUH GUIDED IMAGARY TERHADAP PENURUNAN RASA NYERI PADA PENDERITA GASTRITIS DIRUMAH SAKIT UMUM ROYAL PRIMA MEDAN

Pendahuluan : Gastritis merupakan iritasi pada lambung yang menyebabkan rasa nyeri pada penderitanya. Pada umumnya masyarakat tidak mengenal penyakit gastritis tapi lebih sering mengatakan penyakit maag. Nyeri adalah respon tubuh terhadap rasa sakit. Ada beberapa tindakan yang dapat dilakukan dalam mengatasi rasa nyeri, salah satunya terapi Guided Imagary, Solusi yang aman bagi pasien tanpa efek samping yang diderita, karena pada terapi ini mengolah cara pikir dengan memusatkan pikiran pada hal-hal yang menyenangkan.

Tujuan umum : "Mengetahui pengaruh guided imagary terhadap penurunan rasa nyeri pada pasien penderita gastritis pada Rumah Sakit Umum Royal Prima".

Metode : Jenis penelitian ini yaitu penelitian analitik deskriptif dengan one grup desain pre dan post test, dengan menggunakan variabel independen dan dependen diteliti secara bersamaan yang bertujuan untuk mengetahui "pengaruh Guided Imagary terhadap penurunan rasa nyeri pada pasien penderita Gastritis di Rumah Sakit Umum Royal Prima Medan". Menurut Notoadmojo (2010) "Populasi adalah seluruh objek yang akan diteliti, di dalam penelitian ini" yaitu keseluruhan pasien gastritis di ruangan rawat inap Rumah Sakit Umum Royal Prima Medan sebanyak 38 orang. Sampel adalah pasien gastritis di ruangan rawat inap Rumah Sakit Umum Royal Prima sebanyak 38 orang. Teknik pengambilan sampel ini dengan menggunakan total sampling yaitu seluruh populasi akan dijadikan sampel.

Hasil : Penelitian pre test mayoritas nyeri sedang dan nyeri berat sebanyak 17 responden (44,7\%), dan minoritas tidak ada nyeri dan nyeri ringan 2 responden (5,3\%). Penelitian post test didapati mayoritas sebanyak 18 responden (47,4\%) dan minoritas nyeri berat 3 responden $(7,9 \%$ ). Nilai sig ( 2 tailed) $=0,000$ dan a $=0,05$, maka 0,000 < 0,05 maka Ho ditilak Ha diterima artinya ada pengaruh Guided Imagary terhadap penurunan rasa nyeri pada Gastritis.

Kesimpulan : Bahwa terdapat Pengaruh Guided Imagary Terhadap Penurunan Rasa Nyeri Pada Penderita Gastritis.

Kata kunci : Gastritis, Nyeri, Teknik Guided Imagary

\footnotetext{
Robbialwy Sembiring ${ }^{1}$, Ema Novelia ${ }^{2}$, Merisusanna Sinuhaji ${ }^{3}$, Chrismis Novalinda Ginting $^{4}$

${ }_{1,2,3}$ Mahasiswa S1 Keperawatan Universitas Prima Indonesia. Email : emanovelia02@gmail.com

${ }^{4}$ Dosen Universitas Prima Indonesia. Email : chrismis@unprimdn.ac.id
} 


\section{PENDAHULUAN}

Gastritis merupakan suatu penyakit iritasi lambung sehingga menyebabkan perasaan tidak nyaman dan lambung terasa kembung. Lambung mengalami luka akibat terganggunya fungsi lambung dalam mengolah makanan (Sukarmin, 2013).

Masyarakat sebagian besar kurang mengenal penyakit gastritis, mereka lebih sering mengatakan penyakit maag. Gastritis dapat diketahui dengan cara mewawancarai langsung pasien, tentang apa yang dirasakannya. Penderita gastritis sering mengalami keluhan keluhan dengan perasaan kepala yang pusing, perut yang terasa penuh atau kenyang, perut yang terasa panas dan tidak nyaman, perasaan mual dan ingin merasa muntah (Megawati \& Nossi, 2014).

Nyeri adalah reaksi tubuh terhadap rasa sakit. Setiap orang atau penderita memiliki karakteristik yang berbeda dengan yang lainnya menanggapi rasa nyeri. Terdapat tindakan-tindakan yang dapat dilakukan dalam mengatasi rasa nyeri. Salah satunya Guided imagary therapy adalah cara untuk mengatasi rasa nyeri yang aman bagi pasien tanpa ada efek samping pada sakit yang diderita. Terapi ini dilakukan dengan cara mengolah cara pikir yang menyenangkan sehingga bisa untuk melupakan rasa nyeri, stres dan pikiran-pikiran yang lain. Cara ini dilakukan dengan memusatkan pikiran secara mendalam dan sangat dalam sehingga pasien hanya merasa dia dan pikiran positif yang berada di sekitarnya (Nurhanifah dkk, 2018).

Tehnik guided imagary merupakan cara atau tahap dimana pikiran diolah atau diganti dengan hal-hal yang positif/menyenangkan. Tahapan ini memerlukan tingkat konsentrasi dan pemusatan pikiran sehingga rasa nyeri perlahan-lahan menghilang diganti dengan perasaan yang bahagia dan menyenangkan muncul dalam pikiran. Hal ini efektif terhadap "penurunan rasa nyeri pada pasien gastritis” (Kartika \& Utami, 2018).

Hasil penelitian Jamaluddin menunjukan pola makan adalah salah satu "faktor yang paling berpengaruh dalam kejadian gastritis. Pola makan tidak teratur dapat menyebabkan penyakit gastritis, Apabila seseorang terlambat makan sampai 2-3 jam maka asam lambung yang diproduksi semakin berlebih sehingga dapat mengiritasi mukosa lambung. Jenis makanan, minuman atau obat-obatan yang merangsang asam lambung diantaranya makanan yang pedas, asam, alkohol dan Antiinflamatory Drugs (NSAID). Merokok dan stres juga dapat menyebabkan gastritis karena adanya rangsangan saraf para simpatis yang mengeluarkan asam lambug secara berlebih".

Berdasarkan survei awal yang dilakukan peneliti bahwa angka penderita gastritis di Rumah Sakit Umum Royal Prima pada bulan Januari sampai dengan November 2019 sebanyak pasien rawat inap (tidak dengan pasien berulang). Peneliti juga melakukan observasi berdasarkan status pasien di rekam medik kebanyakan pasien mengeluh karena makan yang tidak tepat waktu dan makan banyak setelah terlambat makan.

Robbialwy Sembiring ${ }^{1}$, Ema Novelia ${ }^{2}$, Merisusanna Sinuhaji ${ }^{3}$, Chrismis Novalinda Ginting $^{4}$

${ }_{1,2,3}$ Mahasiswa S1 Keperawatan Universitas Prima Indonesia. Email : emanovelia02@gmail.com

${ }^{4}$ Dosen Universitas Prima Indonesia. Email : chrismis@unprimdn.ac.id 


\section{METODE PENELITIAN}

Jenis penelitian ini yaitu penelitian analitik deskriptif dengan one grup desain pre dan post test, "dimana variabel independen dan dependen diteliti secara bersamaan yang bertujuan untuk mengetahui pengaruh Guided Imagary terhadap penurunan rasa nyeri pada pasien penderita Gastritis di Rumah Sakit Umum Royal Prima Medan".

Sampel "dalam penelitian ini berjumlah 38 orang dengan menggunakan total sampling". Peneliti melakukan intervensi guided imagary kepada pasien yang sebelum dan sesudah intervensi dilakukan penilaian skala nyeri pasien.

Instrumen

penelitian menggunakan kuesioner dan lembar observasi. Aspek pengukuran terdiri dari tahap pre test dan post test.

Lembar kuesioner berupa : surat permohonan menjadi responden, pernyataan bersedia menjadi responden, standar pelaksanaan guided imagery dan lembar observasi. Dilembar observasi terdapat biodata dan skala intesitas nyeri numeric 0-10 dengan ket : 0 tidak ada nyeri, 1-3 nyeri ringan,4-6 nyeri sedang dan 7-10 nyeri berat.

Didalam penelitian ini sudah dilakukan uji etik Penelitian pada tanggal 20 Mei 2020 dengan no surat : 044/KEPK/UNPRI/V/2020.

Pengumpulan

data menggunakan data primer dan data sekunder. Data primer adalah data yang diperoleh langsung dari pasien ketika mengisi lembaran kuesioner pada saat penelitian dilakukan. Data sekunder diperoleh dari rekam medis.

Tahap pertama peneliti meminta surat survei dari kampus kemudian peneliti mengajukan surat survei penelitian ke RSU Royal Prima Medan. Setelah dikeluarkan izin oleh pihak RSU Royal Prima Medan peneliti melakukan survei tentang jumlah penderita gastritis.

Tahap kedua peneliti meminta surat izin penelitian dari kampus setelah mendapatkan surat izin penelitian dari kampus kemudian peneliti mengajukan surat izin penelitian ke RSU Royal Prima Medan. Setelah dikeluarkanlah izin oleh pihak RSU Royal Prima Medan peneliti melakukan penelitian terhadap pasien gastritis yaitu melihat tingkat nyeri pada pasien gastritis sebelum dilakukan terapi Guided Imagary dan sesudah dilakukan terapi Guided Imaginary. Pengolahan data dengan Editing, Coding, Entrying setelah dilakukan coding, maka dalam software computer salahdata dari kuesioner dimasukkan ke satunya adalah SPSS Versi 16.

Tabulating data yang sudah lengkap diberi tanda sesuai dengan variabelnya kemudian dimasukkan dalam tabel menggunakan system komputerisasi.

Cleaning jika semua data di setiap sumber data atau responden sudah dimasukkan, perlu dilakukan lagi cek ulang untuk melihat kemungkinan adanya kesalahan kode, ketidaklengkapan data dan sebagainya, kemudian dilakukan pembetulan atau koreksi kembali. Proses ini disebut pembersihan data (data cleaning).

Robbialwy Sembiring ${ }^{1}$, Ema Novelia ${ }^{2}$, Merisusanna Sinuhaji ${ }^{3}$,Chrismis Novalinda Ginting ${ }^{4}$

1,2,3 Mahasiswa S1 Keperawatan Universitas Prima Indonesia. Email : emanovelia02@gmail.com

${ }^{4}$ Dosen Universitas Prima Indonesia. Email : chrismis@unprimdn.ac.id 


\section{HASIL PENELITIAN}

Analisa Univariat

Tabel 1 Distribusi Frekuensi Responden Berdasarkan Umur, Jenis Kelamin, Pre test dan Post test

\begin{tabular}{|c|c|c|c|}
\hline No & Variabel & Jumlah (n) & Persentase (\%) \\
\hline \multirow[t]{5}{*}{1} & Umur & & \\
\hline & a. $<35$ tahun & 16 & 42,1 \\
\hline & b. $36-50$ tahun & 16 & 42,1 \\
\hline & c. $>50$ tahun & 6 & 15,8 \\
\hline & Total & 38 & 100 \\
\hline \multirow[t]{4}{*}{2} & Jenis kelamin & & \\
\hline & a. Laki-laki & 24 & 63,2 \\
\hline & b. Perempuan & 14 & 36,8 \\
\hline & Total & 38 & 100 \\
\hline \multirow[t]{6}{*}{3} & Pra test & & \\
\hline & a. Tidak ada nyeri & 2 & 5,3 \\
\hline & b. Nyeri ringan & 2 & 5,3 \\
\hline & c. Nyeri sedang & 17 & 44,7 \\
\hline & d. Nyeri parah & 17 & 44,7 \\
\hline & Total & 38 & 100 \\
\hline \multirow[t]{6}{*}{4} & Post test & & \\
\hline & a. Tidak ada nyeri & 4 & 10,5 \\
\hline & b. Nyeri ringan & 18 & 47,4 \\
\hline & c. Nyeri sedang & 13 & 34,2 \\
\hline & d. Nyeri parah & 2 & 7,9 \\
\hline & Total & 38 & 100 \\
\hline
\end{tabular}

Berdasarkan tabel 1, variabel umur mayoritas < 35 tahun dan 36-50 tahun ada 16 responden $(42,1 \%)$ dan minoritas > 50 tahun ada 6 responden (15,8\%). Variabel jenis kelamin mayoritas laki-laki ada 24 responden $(63,2 \%)$ dan minoritas perempuan ada 14 responden $(36,8 \%)$. Variabel pra test mayoritas

\section{Analisa Bivariat}

Pengaruh Guided Imagary terhadap "penurunan rasa nyeri pada pasien penderita Gastritis di Rumah Sakit Umum Royal Prima Medan dapat dilihat pada tabel di bawah" : nyeri sedang dan nyeri parah sebanyak 17 responden $(44,7 \%)$ dan minoritas tidak ada nyeri dan nyeri ringan sebanyak 2 responden (5,3\%). Variabel post test mayoritas nyeri ringan sebanyak 18 orang $(47,4 \%)$ dan minoritas nyeri parah sebanyak 3 responden $(7,9 \%)$.

Robbialwy Sembiring ${ }^{1}$, Ema Novelia ${ }^{2}$, Merisusanna Sinuhaji ${ }^{3}$, Chrismis Novalinda Ginting $^{4}$ ${ }^{1,2,3}$ Mahasiswa S1 Keperawatan Universitas Prima Indonesia. Email : emanovelia02@gmail.com ${ }^{4}$ Dosen Universitas Prima Indonesia. Email : chrismis@unprimdn.ac.id 
Tabel 2 Pengaruh Guided Imagary terhadap penurunan rasa nyeri pada penderita Gastritis

\begin{tabular}{lcccccc}
\hline & Mean & $\begin{array}{c}\text { Standart } \\
\text { deviation }\end{array}$ & $\begin{array}{c}\text { Standart } \\
\text { error }\end{array}$ & $T$ & Df & $\begin{array}{c}\text { Sig (2 } \\
\text { tailed) }\end{array}$ \\
\hline $\begin{array}{l}\text { Pra test - } \\
\text { Post test }\end{array}$ & 0,895 & 0,831 & 0,135 & 6,634 & 37 & 0,000 \\
\hline
\end{tabular}

Berdasarkan hasil uji paired sampel testT-Test "Pengaruh Guided Imagary terhadap penurunan rasa nyeri pada pasien penderita Gastritis di Rumah Sakit Umum Royal Prima Medan dengan nilai sig (2tailed) $=$ 0,000 dan $a=0,05$, maka $0,000<$
0,05 maka Ho tidak diterima $\mathrm{Ha}$ diterima artinya ada pengaruh Guided Imagary terhadap penurunan rasa nyeri pada pasien penderita Gastritis di Rumah Sakit Umum Royal Prima Medan".

\section{PEMBAHASAN}

1. Karakteristik responden berdasarkan umur dan jenis kelamin

Hasil penelitian yang dilakukan Sunarmi (2018) tentang "FaktorFaktor Yang Berisiko terhadap Kejadian Penyakit Gastritis di Poliklinik Penyakit Dalam Rumah Sakit Muhammadiyah Palembang Tahun2018, diperoleh bahwa faktor umur dan faktor jenis kelamin tidak berpengaruh terhadap kejadian gastritis". Peneliti menemukan bahwa mayoritas pasien yang ditemukan sebagai sampel dalam penelitian mayoritas ada dua kelompok usia yaitu, kurang dari 35 tahun dan 35 tahun sampai berumur 50 tahun. Pasien yang berumur lebih dari 50 tahun hanya berjumlah 6 orang. Peneliti juga menemukan bahwa pasien yang menjadi sampel pada penelitian tersebut "berjenis kelamin laki-laki dan lebih banyak dari pada perempuan berjumlah hanya 14 orang".

\section{Pre test}

Peradangan yang terjadi di dalam lambung mempengaruhi fungsi setiap organ dalam lambung. Sel-sel yang terdapat di dalam lambung secara perlahan-lahan tidak dapat berjalan sesuai dengan fungsinya. Hal ini dikarenakan peradangan di dalam lambung meningkatkan zat asam di dalam lambung sehingga lambung terasa penuh. Zat asam mengganggu kinerja sel-sel di dalam lambung dan terjadi penumpukan zat asam yang perlahan-lahan mengganggu permukaan lambung sehingga permukaan lambung terasa nyeri (Ode, 2016).

$\begin{array}{llr}\text { Hasil } & \text { penelitian } & \text { yang } \\ \text { dilakukan } & \text { Supetran, } & \text { tentang } \\ \text { "efektifitas penggunaan } & \text { teknik } \\ \text { relaksasi otot progresif } & \text { dalam }\end{array}$
penurunan tingkat nyeri pada pasien Gastritis di Rumah Sakit Daerah Madani Palu diperoleh hasil bahwa seluruh pasien gastritis sebelum menerapkan terapi relaksasi mengalami perasaan kurang nyaman atau nyeri" (Supetran, 2016).

Peneliti menemukan bahwa ada 4 jenis nyeri yang di alami pada penelitian diantaranya, tidak ada nyeri sebelum tindakan, nyeri ringan sebelum tindakan, nyeri sedang sebelum tindakan, dan nyeri parah sebelum tindakan. Pada saat penelitan di rumah sakit, peneliti

Robbialwy Sembiring ${ }^{1}$, Ema Novelia ${ }^{2}$, Merisusanna Sinuhaji ${ }^{3}$,Chrismis Novalinda Ginting ${ }^{4}$

${ }_{1,2,3}$ Mahasiswa S1 Keperawatan Universitas Prima Indonesia. Email : emanovelia02@gmail.com

${ }^{4}$ Dosen Universitas Prima Indonesia. Email : chrismis@unprimdn.ac.id 
menemukan bahwa mayoritas pasien sebelum tindakan lebih banyak menderita nyeri sedang dan nyeri parah, dan sisanya tidak ada nyeri dan nyeri ringan pada saat tindakan berlangsung.

\section{Post test}

Terapi guided imagary mempengaruhi pasien gastritis sehingga merasa nyaman. Pasien gastritis merasa nyaman ketika melalui tahapan-tahapan dengan perlahan-lahan tidak mengingat lagi adanya rasa nyeri di dalam lambung. Tahapan-tahapan ini mempengaruhi keadaan tingkat nyeri yang dialami pasien gastritis semakin berkurang (Kartika \& Utami, 2018). Hasil penelitian yang dilakukan Supetran (2016) "efektifitas penggunaan teknik relaksasi otot progresif dalam penurunan tingkat nyeri pada pasien Gastritis di Rumah Sakit Daerah Madani Palu diperoleh hasil bahwa mayoritas pasien gastritis setelah menerapkan terapi relaksasi mengalami perasaan nyaman".

Peneliti menemukan bahwa setelah dilakukanya tindakan terjadi bahwa ada perubahan yang dialami pada pasien tersebut diantara, menjadi nyeri ringan sebanyak hampir mendekati $50 \%$ dan diikuti oleh nyeri sedang dan tidak ada nyeri atau rasa nyeri hilang.hanya sebagian kecil pasien yang mengalami peningkatan rasa nyeri yang semakin parah.

\section{Uji Paired sample test}

Nilai sig (2 tailed) $=0,000$ dan " $\alpha=0,05$, maka $0,000<0,05$ " maka $\mathrm{Ho}$ tidak diterima $\mathrm{Ha}$ diterima artinya ada "pengaruh Guided Imagary terhadap penurunan rasa nyeri pada pasien penderita
Gastritis di Rumah Sakit Umum Royal Prima Medan".

Hasil penelitian yang dilakukan "Dewi Nurhanifah, Annisa Resa Nur Afni, Rahmawati tentang pengaruh Guided Imagary terhadap penurunan nyeri pada pasien penderita Gastritis di Wilayah Kerja Puskesmas di Banjarmasin, menunjukan bahwa tapat pengaruh pelaksanaan Guided imagary terhadap penurunan rasa nyeri pada klien gastritis di Wilayah Kerja Puskesmas Karang Mekar Banjarmasin" (Nurhanifah dkk,2018) Setelah peneliti mengolah data dari hasil yang telah dilaksanakan didapati bahwa nilai yang didapat kurang dari 0,05. Ini "berarti bahwa selama ada pengaruh pemberian terapi guided imaginary pada pasien penderita gastritis di Rumah Sakit Royal Prima Medan. Apabila nilai tersebut lebih dari 0.05 berarti bahwa tidak ada pengaruh selama dilakukan tindakan tersebut pada pasien".

\section{KESIMPULAN}

Hasil penelitian "Pengaruh Guided Imagary Terhadap Penurunan Rasa Nyeri Pada pasien Penderita Gastritis di Rumah Sakit Umum Royal Prima Medan"

Variabel umur mayoritas $<35$ tahun dan 36-50 tahun ada 16 responden $(42,1 \%)$ dan minoritas > 50 tahun ada 6 responden (15,8\%).

Variabel jenis kelamin mayoritas laki-laki ada 24 responden $(63,2 \%)$ dan minoritas perempuan ada 14 responden $(36,8 \%)$.

Variabel pra test mayoritas nyeri sedang dan nyeri parah sebanyak 17 responden $(44,7 \%)$ dan minoritas tidak ada nyeri dan nyeri ringan sebanyak 2 responden (5,3\%).

Sedangkan Variabel post test mayoritas nyeri ringan sebanyak 18

Robbialwy Sembiring ${ }^{1}$, Ema Novelia ${ }^{2}$, Merisusanna Sinuhaji ${ }^{3}$,Chrismis Novalinda Ginting ${ }^{4}$

${ }_{1,2,3}$ Mahasiswa S1 Keperawatan Universitas Prima Indonesia. Email : emanovelia02@gmail.com

${ }^{4}$ Dosen Universitas Prima Indonesia. Email : chrismis@unprimdn.ac.id 
orang $(47,4 \%)$ dan minoritas nyeri parah sebanyak 3 responden $(7,9 \%)$.

Nilai sig (2tailed) $=0,000$

dan $a=0,05$, maka $0,000<0,05$ maka Ho tidak diterima $\mathrm{Ha}$ diterima artinya ada pengaruh Guided Imagary terhadap penurunan rasa nyeri pada pasien penderita Gastritis di Rumah Sakit Umum Royal Prima Medan.

\section{SARAN}

\section{Bagi Rumah sakit}

Agar dapat memberikan informasi tentang tahap-tahap pelaksanan terapi Guided Imagary sehingga pasien gastritis memahami cara pelaksanaan dan mampu menerapkan "terapi Guided Imagary sehingga dapat merasakan efeknya terhadap penurunan rasa nyeri pada pasien penderita gastritis di Rumah Sakit Umum Royal Prima Medan”.

\section{Peneliti Selanjutnya}

Sebagai gambaran untuk peneliti selanjut nya tentang pengaruh guided imagary terhadap penurunan rasa nyeri pada penderita gastritis di rumah sakit umum royal prima medan

\section{DAFTAR PUSTAKA}

Adwan., Ratu. (2013). Penyakit Hati, lambung, Usus dan Embeien, Penerbit Nuha Medika, Yogyakarta

Agianto. ( 2017). Gambaran Kejadian Gastritis di RSUD Ratu Zalecha Martapura, Dunia Keperawatan, Volume 4, Nomor 1, Maret 2016: 48-54

Arikunto. (2010). Prosedur Penelitian Suatu Pendekatan Praktik, Penerbit Rineka Cipta, Jakarta
Burhan. (2018). Hubungan Pola Makan dan Tingkat Stres terhadap Kekambuhan Gastritis di Wilayah Kerja Puskesmas Tarok Kota Payakumbuh Tahun 2017, Jurnal Kesehatan Andalas.

Dewi. (2014). Faktor-Faktor Yang Mempengaruhi Terjadinya Gastritis di Wilayah Kerja Puskesmas Tamalanrea Makassar, ,

Hasnah., Mappagerang. (2017). Hubungan Tingkat Stres Dan Pola Makan Dengan Kejadian Gastritis Diruang Rawat Inap RSUD Nene Mallomo Kabupaten Sidrap JIKP@Jurnal Ilmiah Kesehatan Pencerah, Volume 6 Nomor 1.

Ismail. (2018). Faktor Determinan Gastritis Klinis Pada Mahasiswa di Fakultas Kesehatan Masyarakat Universitas Halu Oleo Tahun 2016, Jurnal IImiah Mahasiswa Kesehatan Masyarakat, Vol. 2/NO.6/ Mei 2017; ISSN 250-731X

Kartika., Utami. (2018). Terapi Komplementer Guna Menurunkan Nyeri Pasien Gastritis: Literatur Review, diakses tanggal 2 Desember 2019

Killing. (2019). Hubungan Penanganan Awal Gastritis Dengan Skala Nyeri Pasien UGD Rumah Sakit Gmim Bethesda Tomohon, e-journal Keperawatan (e-Kep) Volume 7 Nomor

Robbialwy Sembiring ${ }^{1}$, Ema Novelia ${ }^{2}$, Merisusanna Sinuhaji ${ }^{3}$,Chrismis Novalinda Ginting ${ }^{4}$

1,2,3 Mahasiswa S1 Keperawatan Universitas Prima Indonesia. Email : emanovelia02@gmail.com

${ }^{4}$ Dosen Universitas Prima Indonesia. Email : chrismis@unprimdn.ac.id 
Kurniawan. (2016). Narrative review: terapi komplementer alternatif akupresur dalam Menurunkan tingkat nyeri, NurseLine Journal Vol. 1 No. 2

Marandin. (2014). Pengkajian Skala Nyeri di Ruang Perawatan Intensive Literatur Review, tanggal 2 Desember 2019

Megawati., Nossi. (2014). Beberapa Faktor Yang Berhubungan Dengan Kejadian Gastritis Pada Pasien Yang di Rawat di RSUD Labuang Baji Makassar, diakses tanggal 2 Desember 2019

Notoatmodjo. S. (2010). Metodologi Penelitian Kesehatan. Rineka Cipta, Jakarta.

Nurhanifah. (2018). Pengaruh Guided Imaginary Terhadap Penurunan Nyeri Pada Klien Gastritis Di Wilayah Kerja Puskesmas Di Banjarmasin, diakses tanggal 2 Desember 2019

Ode. (2016). Asuhan Keperawatan Gerontik, Penerbit Nuha Medika, Yogyakarta
Purwanto. (2013). Herbal dan Keperawatan Komplementer, Diterbitkan Nuha Medika, Yogyakarta

Selviana. (2015). Effect of Coffee And Stress With The Incidence of Gastritis, diakses tanggal 2 Desember 2019

Siagian. (2012). Gambaran Pola Makan Penderita Gastritis Di Wilayah Kerja Puskesmas Kampar Kiri Hulu Kecamatan Kampar Kiri Hulu Kabupaten Kampar Riau

Sukarmin. (2013). Keperawatan Pada Sistem Pencernaan, Penerbit Pustaka Pelajar, Yogyakarta

Sunarmi. (2018) Faktor-Faktor Yang Berisiko Dengan Kejadian Penyakit Gastritis Di Poliklinik Penyakit Dalam Rumah Sakit Muhammadiyah Palembang, Volume 8.

Supetra. (2016). Efektifitas Penggunaan Teknik Relaksasi Otot Progresif Dalam Menurunkan Tingkat Nyeri Pasien Gastritis di Rumah Sakit Daerah Madani Palu, Promotif, Vol.6 No.1, Hal 01-08.

\footnotetext{
Robbialwy Sembiring ${ }^{1}$, Ema Novelia ${ }^{2}$, Merisusanna Sinuhaji ${ }^{3}$,Chrismis Novalinda Ginting ${ }^{4}$ ${ }_{1,2,3}$ Mahasiswa S1 Keperawatan Universitas Prima Indonesia. Email : emanovelia02@gmail.com ${ }^{4}$ Dosen Universitas Prima Indonesia. Email : chrismis@unprimdn.ac.id
} 